\title{
Extended Spectrum- $\beta$-Lactamase or Carbapenemase Producing Bacteria Isolated from Patients with Acute Cholangitis
}

\author{
Ja Chung Goo', Mun Hyuk Seong', Young Kwang Shim¹, Hee Seung Lee', Jung-Ho Han', \\ Kyeong Seob Shin ${ }^{2}$, Jae-Woon Choi ${ }^{3}$, Sei Jin Youn ${ }^{1}$ and Seon Mee Park ${ }^{1}$ \\ Departments of ${ }^{1}$ Internal Medicine, ${ }^{2}$ Laboratory Medicine and \\ ${ }^{3}$ General Surgery, Chungbuk National University College of Medicine, Cheongju, Korea
}

See commentary on page 111

Background/Aims: This study assessed the antibiotic resistance organisms isolated from the blood and bile of acute cholangitis and evaluated risk factors associated with them and their impact on clinical outcomes.

Methods: The identities and antibiotic resistance profiles of bacteria isolated from 433 cases of acute cholangitis from 346 patients were analyzed. Risk factors and the outcomes of patients infected with them were assessed.

Results: Microorganisms were isolated from 266 of 419 blood cultures and 256 of 260 bile cultures. Isolates from bile and blood were identical in $71 \%$ of the cases. A total of 20 extended spectrum- $\beta$-lactamase (ESBL)-producers and 4 carbapenemase-producing organisms were isolated from blood, and 34 ESBL-producers and 13 carbapenemase-producers were isolated from bile. Sixty-four (14.8\%) cases were infected with any one of these bacteria isolated from blood or bile. Risk factors associated with them in blood were nosocomial infection and prior biliary intervention. In bile, indwelling biliary device was a risk factor associated with them. Antibiotic-resistant bacteria were associated with mortality, independent of other prognostic factors.

Conclusions: ESBL or carbapenemase-producing bacteria were frequently isolated in acute cholangitis patients especially with prior biliary intervention and nosocomial infection. Isolation of antibiotic-resistant bacteria was an independent risk factor of mortality.

Key Words: Acute cholangitis; Bile culture; Blood culture; Microbial drug resistance

\section{INTRODUCTION}

Acute cholangitis is most commonly caused by infection in an obstructed biliary tract. Because bacteria that ascend the biliary tree from duodenum is the main source of bacteriobilia, gram-negative enteric bacteria are the main pathogens associated with it. ${ }^{1}$ Administration of broad-spectrum antibiotics is recommended until the results of culture are available. ${ }^{2}$

Received: July 25, 2011 Revised: December 6, 2011

Accepted: December 29, 2011

Correspondence: Seon Mee Park

Department of Internal Medicine, Chungbuk National University Hospital, Chungbuk National University College of Medicine, 410 Seongbong-ro, Heungdeok-gu, Cheongju 361-711, Korea

Tel: +82-43-269-6019, Fax: +82-43-27-3252, E-mail: smpark@chungbuk.ac.kr (c) This is an Open Access article distributed under the terms of the Creative Commons Attribution Non-Commercial License (http://creativecommons.org/ licenses/by-nc/3.0) which permits unrestricted non-commercial use, distribution, and reproduction in any medium, provided the original work is properly cited.
However, in recent years, some studies have reported that isolates from acute cholangitis patients have changed due to the frequent use of biliary devices and prior exposure to antibiotics. ${ }^{3,4}$ The major problem for infection control is the spread of extended spectrum- $\beta$-lactamase (ESBL)-producing organisms in the community as well as in the nosocomial setting. ${ }^{5,6} \mathrm{ESBL}$ hydrolyzes cephalosporins and confers resistance to most $\beta$-lactams antibiotics. The rate of isolation of ESBL-producing gram negative bacteria is higher in Asia, including Korea, than in other regions. ${ }^{7}$ Bacteremia caused by ESBL-producing bacteria results in high mortality unless appropriate antibiotics are administered. Thus, it is important to regularly survey the rate of infections caused by ESBL-producing bacteria. ${ }^{8}$ In addition, the emergence of carbapenemase-producing bacteria is a major public health concern, because carbapenem is the most reliable therapeutic agent for ESBL-producing bacteria. ${ }^{9}$ These bacteria may be intractable to the usual antibiotics and have a 
significant impact on clinical outcomes. Thus, a survey of the profile of organisms that cause acute cholangitis is needed for proper antibiotic selection. However, most of the few studies that have been published on this subject used only a small sample size, showing different results among them..$^{10-15}$

We analyzed the organisms isolated from the blood and bile of patients with acute cholangitis and determined their antibiotic resistance characteristics. In addition, we evaluated risk factors associated with antibiotic-resistant bacteria and their impact on clinical outcomes.

\section{MATERIALS AND METHODS}

\section{Patients}

We enrolled consecutive cases of acute cholangitis at Chungbuk National University Hospital from July 2000 to June 2009. Organisms of bile or blood were isolated from 433 cases of acute cholangitis from 346 patients. Acute cholangitis was diagnosed by Charcot's triad (fever or chills, jaundice, and abdominal pain) or two or more clinical manifestations (history of biliary diseases and Charcot's triad) and laboratory data showing evidence of inflammatory response and abnormal liver function tests, and imaging findings of biliary dilatation or evidence of etiology. ${ }^{16}$ Severe cholangitis was defined when it was associated with at least any one of the following organ dysfunction; hypotension, conscious disturbance, $\mathrm{PaO}_{2} / \mathrm{FiO}_{2}$ ratio $<300$, serum creatinine $>2.0 \mathrm{mg} / \mathrm{dL}$, PT-INR $>1.5$ or platelet count $<1.0$ $\times 10^{5} / \mu \mathrm{L} .{ }^{16} \mathrm{Empirical}$ antibiotics were applied with intravenous cefotaxime, and intravenous metronidazole was added in severe cholangitis. The infected bile was treated by drainage with endoscopic retrograde cholangiopancreatography (ERCP) or percutaneous transhepatic biliary drainage (PTBD) if biliary obstruction was present. Intraductal bile specimens were collected during ERCP or PTBD procedures from 260 cases. Specimens were transferred into a sterile collection tube prior to culturing. Blood cultures were also obtained from 419 cases. Usually, $5 \mathrm{~mL}$ blood was obtained and transferred into aerobic and anaerobic culture bottles, with at least two specimens obtained per case.

\section{Clinical data collection}

Underlying biliary diseases were classified as either malignant or benign. Cases with previous biliary interventions, such as biliary stents, PTBD, endoscopic sphincterotomy (EST), and operation, before acute cholangitis were identified. Recurrence was defined as the occurrence of more than two cases of acute cholangitis in one individual. Bacteria isolated within 48-hours of hospitalization were considered community-acquired. We also analyzed risk factors related to mortality.

\section{Identification and antimicrobial characterization of causative organisms}

Blood cultures were analyzed using an automated system (BacTAlert 3D; bioMérieux, Marcy l'Etoile, France), and the isolates were identified by conventional methods including the Vitek system using a GNI or GPI card (bioMérieux, Hazelwood, MO, USA). Antibiotic susceptibility tests were conducted using either the Vitek system or the disc diffusion method according to the Clinical Laboratory Standards Institute (CLSI) guidelines. ${ }^{17} \mathrm{ESBL}$ production was assessed using the CLSI screening test and confirmed by the double-disk test (20/10 g; BBL Microbiology System, Cockeysville, MD, USA) and a cefotaxime (30 g; BBL Microbiology System), ceftazidime (30 g; BBL Microbiology System), aztreonam (30 g; BBL Microbiology System) or cefepime disk (30 g; BBL Microbiology System). Carbapenemase production was determined using the modified Hodge test. Vancomycin resistance was screened using vancomycin disk (30 g; BBL Microbiology System) diffusion and confirmed by the E test (AB Biodisk, Solna, Sweden) in Enterococci. Methicillin resistance Staphylococcus aureus (MRSA) was determined using an oxacillin (1 g; BBL Microbiology System) or cefoxitin disk (30 g; BBL Microbiology System).

\section{Causative profiles and antibiotic-resistant bacteria}

The microbiological results of blood and bile cultures were analyzed. The positive rates of blood or bile cultures and instances where the same organisms were isolated from both blood and bile were evaluated. Isolation rates of ESBL or carbapenemase producers, multidrug resistant (MDR) Acinetobacter species, MRSA, and Vancomycin-resistant Enterococcus (VRE) were evaluated. Multivariate analysis was performed to identify risk factors associated with resistant bacteria and the prognostic factors of mortality.

All statistical analysis were performed using a statistical software package (SPSS version 12.0 for Windows; SPSS Inc., Chicago, IL, USA). Statistical analysis was performed using either Pearson's chi-square test, linear by linear association, or logistic regression analysis, as appropriate. Statistical significance was defined as a $p$-value of $<0.05$ (two-tailed).

\section{RESULTS}

\section{Characteristics of acute cholangitis}

The underlying biliary diseases were choledocholithiasis in 187 (54.0\%) patients, and malignant and benign strictures in $146(42.2 \%)$ and $13(3.8 \%)$ patients, respectively. Severe cholangitis occurred in 107 (24.7\%) cases. Three hundred sixtyseven $(84.8 \%)$ cases developed cholangitis in community setting. Two hundred seventeen (50.1\%) cases received prior bilia- 
Table 1. Characteristics of First and Recurrent Episodes of Acute Cholangitis

\begin{tabular}{|c|c|c|c|c|}
\hline Parameter & No. of cases & First episode $(n=268)$ & Recurrent episode $(n=165)$ & $p$-value \\
\hline Age & & $68 \pm 13$ & $69 \pm 11$ & NS \\
\hline Sex & & & & NS \\
\hline Male & 231 & 146 & 85 & \\
\hline Female & 202 & 122 & 80 & \\
\hline \multicolumn{5}{|l|}{ Underlying Biliary diseases } \\
\hline Choledocholithiasis & $218(74)$ & $142(53.0)$ & $76(46.1)$ & NS \\
\hline Benign stricture & 19 & $11(4.1)$ & $8(4.8)$ & \\
\hline Malignant stricture & $196(75)$ & $115(42.9)$ & $81(49.1)$ & \\
\hline Severe cholangitis & & & & NS \\
\hline Yes & 107 & $68(25.4)$ & $39(23.6)$ & \\
\hline No & 326 & $200(74.6)$ & $126(76.4)$ & \\
\hline Community or hospital acquired & & & & $<0.0001$ \\
\hline Community acquired & 367 & $215(80.2)$ & $152(92.1)$ & \\
\hline Hospital acquired & 66 & $53(19.8)$ & $13(7.9)$ & \\
\hline Prior biliary intervention & & & & $<0.0001$ \\
\hline None & 216 & $199(74.3)$ & $17(10.3)$ & \\
\hline EST & 78 & $16(6.0)$ & $62(37.6)$ & \\
\hline PTBD & 57 & $22(8.2)$ & $35(21.2)$ & \\
\hline Biliary stent & 69 & $23(8.6)$ & $46(27.9)$ & \\
\hline Operation & 13 & $8(3.0)$ & $5(3.0)$ & \\
\hline Clinical outcomes & & & & NS \\
\hline Recovered & 400 & $251(93.7)$ & $149(90.3)$ & \\
\hline Expired & 33 & $17(6.3)$ & $16(9.7)$ & \\
\hline
\end{tabular}

Values are presented as mean \pm SD or number (\%).

NS, non significant; EST, endoscopic sphincterotomy; PTBD, percutaneous transhepatic biliary drainage.

ry intervention; EST in 78 cases, PTBD in 57 cases, biliary stent in 69 cases, and surgery in 13 cases. Recurrent cholangitis occurred in $165(38.1 \%)$ cases (Table 1$)$.

\section{Profiles of organisms isolated from blood and bile}

Causative organisms were isolated from 266 of 419 (63.4\%) blood cultures and 256 of 260 (98.5\%) bile cultures. Isolates from bile and blood were identical in $71 \%$ of cases. Escherichia coli was the most common bacterium isolated and was present in $40 \%$ of blood and $22 \%$ of bile specimens. The four most common bacterial species isolated from blood were E. coli, Klebsiella pneumoniae, Enterococcus spp., and Pseudomonas aeruginosa, and those from bile were E. coli, P. aeruginosa, Enterococcus spp., and Enterobacter spp. Anaerobic bacteria (Bacteroides fragilis) were isolated from only five blood specimens (Table 2). The rates of multiple organism isolation were 49 of $266(18.4 \%)$ in blood and 100 of 256 (39.1\%) in bile. Enterococcus species were frequently isolated from polymicrobial infections in both blood ( $14.7 \%$ vs. $6.0 \% ; p=0.013)$ and bile $(18.2 \%$ vs. $10.9 \%$; $p=0.058)$ specimens.

\section{The rates and risk factors of antibiotic-resistant bacteria}

The antibiotic-resistant bacteria isolated from blood included 20 ESBL-producing and 4 carbapenemase-producing organisms. Those isolated from bile included 34 ESBL-producing bacteria, 13 carbapenemase-producing bacteria, 3 MDR Acinetobacter, 1 VRE, and 1 MRSA. Resistant bacteria comprised $7.4 \%$ of blood and $13.6 \%$ of bile isolates. Sixty-nine (15.9\%) cases were comprised with any one of antibiotic-resistant bacteria isolated from blood or bile. Risk factors associated with ESBL or carbapenemase-producing organisms from blood were prior biliary intervention $(p=0.016)$ and nosocomial infection ( $p=$ $0.048)$. In bile, indwelling biliary devices $(p=0.024)$ was a risk factor associated with them (Table 3).

\section{The effect of antibiotics resistant bacteria on the mortality}

A total of 33 out of 346 patients died during acute cholangitis cases. Twenty-seven patients with biliary malignancy, one with primary sclerosing cholangitis, and five with choledocho- 
Table 2. Bacteria Isolated from Blood and Bile in Acute Cholangitis cases

\begin{tabular}{lcc}
\hline Bacteria & Isolates in blood & Isolates in bile \\
\hline Aerobic gram (-) bacteria & & \\
Escherichia coli & $130(39.9)$ & $83(22.1)$ \\
Klebsiella pneumoniae & $56(17.2)$ & $43(11.4)$ \\
Pseudomonas aeruginosa & $23(7.1)$ & $59(15.7)$ \\
Enterobacter sp. & $16(4.9)$ & $47(12.5)$ \\
Acinotobacter sp. & $1(0.3)$ & $6(1.6)$ \\
Other enterobacteriaceae & $9(2.8)$ & $37(9.8)$ \\
Aerobic gram (+) bacteria & & \\
Enterococcus & $29(8.9)$ & $57(15.2)$ \\
Coagulase negative & $20(6.1)$ & $0(0.0)$ \\
staphylococcus & & \\
Stenotrophomonas maltophila & $2(0.6)$ & $10(2.7)$ \\
Other glucose-nonfermenter & $17(5.2)$ & $20(5.3)$ \\
Streptococcus pneumoniae & $2(0.6)$ & $1(0.3)$ \\
Streptococcus viridans & $8(2.5)$ & $6(1.6)$ \\
Others & $11(4.0)^{\mathrm{a})}$ & $6(1.6)$ \\
Total bacterial species & $326(100)$ & $376(100)$ \\
\hline
\end{tabular}

Values are presented as number (\%).

a) Bacteroides fragilis 5 cases, candida spp. 2 cases, yeast 2 cases, and others 2 cases.

Table 3. Multivariate Analysis of Risk Factors Associated with ESBL or Carbapenemase Producing Bacteria from Blood or Bile in Acute Cholangitis

\begin{tabular}{lccc}
\hline Variable & $p$-value & Odds ratio & $95 \% \mathrm{CI}$ \\
\hline Blood & & & \\
$\quad$ Hospital acquired & 0.050 & 2.6 & $1.0-6.9$ \\
$\quad$ Prior biliary intervention & 0.006 & 4.4 & $1.5-12.8$ \\
$\quad$ Malignant biliary obstruction & 0.673 & 0.8 & $0.3-2.1$ \\
Bile & & & \\
Hospital acquired & 0.106 & 1.9 & $0.9-4.0$ \\
Recurrent cholangitis & 0.580 & 1.2 & $0.6-2.5$ \\
Indwelling biliary device & 0.047 & 2.3 & $1.0-5.4$ \\
Malignant biliary obstruction & 0.911 & 1.0 & $0.5-2.3$ \\
\hline
\end{tabular}

ESBL, extended spectrum- $\beta$-lactamase; CI, confidence interval.

lithiasis expired during an episode of acute cholangitis. Risk factors associated with mortality were malignant biliary obstruction, severe cholangitis, nosocomial infection, and isolation of antibiotics-resistant bacteria in bile or blood (Table 4). Multivariate analysis revealed that isolation of antibiotic-resistant bacteria was associated with mortality, independent of other prognostic factors such as malignant biliary obstruction and severe cholangitis (Table 5).

\section{DISCUSSION}

Acute cholangitis results from cholestasis and bacteriobilia. ${ }^{1}$ Generally, bacteriobilia alone does not cause acute cholangitis. Obstruction of the bile duct causes an increase in intraductal pressure. Presence of pus under pressure in the bile ducts leads to rapid spread of bacteria via the hepatic sinusoids into the systemic circulation, causing septicemia..$^{18}$ In the present study, all acute cholangitis cases had structural abnormalities in biliary tract.

Bacteria can be isolated from $21 \%$ to $71 \%$ of blood and $80 \%$ to $100 \%$ of bile specimens from individuals with acute cholangitis. ${ }^{10,15}$ In this study, causative organisms were isolated from $63.4 \%$ of blood specimen and $98.5 \%$ of bile culture. Because the organisms isolated from blood reflect a similar distribution to those from biliary cultures, bile culture can provide important information for antibiotic selection. ${ }^{19,20}$ In this study, identical bacteria were isolated from both bile and blood in $71 \%$ of cases.

Antibiotic-resistant bacteria such as ESBL or carbapenemase producers, VRE, and MRSA are recalcitrant to clearance with the most commonly employed antibiotics. ${ }^{21}$ VRE and MRSA play only a minor role in acute cholangitis; however, antibiotic resistance mediated by production of ESBL and/or carbapenemase has become an obstacle to treating acute cholangitis. ${ }^{5,9}$ The antimicrobial surveillance studies has revealed a generalized rise in antibiotic resistance over time. ${ }^{21}$ Recent data from the global Study for Monitoring Antimicrobial Resistance Trends showed that in the Asia-Pacific region and in Latin America, $40 \%$ and $30 \%$ of E. coli and Klebsiella spp. respectively, from patients with intra-abdominal infections were ESBL-positive. ${ }^{22}$ In this study, 64 (14.8\%) cases were infected with any one of ESBL or carbapenemase producing bacteria isolated from blood or bile. These data showed antibiotic-resistant bacteria were frequently isolated in acute cholangitis patients, suggesting the importance of recognizing recent changes in antibiotic-resistant profiles in these patients.

A recent study of community-acquired urinary tract infections showed that ESBL-producing E. coli was frequently isolated from subjects who had used antibiotics previously, those with recurrent infection, and in those who had undergone invasive urinary tract procedures. ${ }^{7}$ The emergence of metallo-lactamases with activity against carbapenems has compromised the clinical utility of this class of antibiotic. One study showed that the risk factors for carbapenem-resistant $E$. coli acquisition are previous use of carbapenem and metronidazole, presence of a biliary drainage catheter, and prior hospital stay. ${ }^{23}$ These data demonstrate that ESBL- or carbapenemase-producing organisms are isolated frequently from cases with previous exposure to several antibiotics or bacterial colonization of indwell- 
Table 4. Characteristics of Acute Cholangitis according to Clinical Outcomes

\begin{tabular}{|c|c|c|c|c|}
\hline Parameter & No. of cases & Death $(n=33)$ & Improved $(n=400)$ & $p$-value \\
\hline \multicolumn{2}{|l|}{ Age } & $68 \pm 14$ & $69 \pm 12$ & NS \\
\hline \multicolumn{4}{|l|}{ Sex } & NS \\
\hline Male & 231 & 19 & 212 & \\
\hline Female & 202 & 14 & 188 & \\
\hline \multicolumn{4}{|c|}{ Underlying biliary diseases } & $<0.0001$ \\
\hline Choledocholithiasis & 218 & $5(15.2)^{\mathrm{a})}$ & $213(53.3)$ & \\
\hline Benign stricture & 19 & $1(3.0)^{\mathrm{b})}$ & $18(4.5)$ & \\
\hline Malignant stricture & 196 & $27(81.8)$ & $169(42.3)$ & \\
\hline \multicolumn{4}{|l|}{ Severe cholangitis } & $<0.000$ \\
\hline Yes & 107 & $20(60.6)$ & $87(21.8)$ & \\
\hline No & 326 & $13(39.4)$ & $313(78.3)$ & \\
\hline \multicolumn{4}{|c|}{ Community or hospital acquired } & 0.021 \\
\hline Community acquired & 367 & $23(69.7)$ & $344(86.0)$ & \\
\hline Hospital acquired & 66 & $10(30.3)$ & $56(14.0)$ & \\
\hline \multicolumn{4}{|c|}{ Isolation of antibiotics resistant bacteria in bile or blood } & $<0.0001$ \\
\hline Yes & 69 & $14(42.4)$ & $55(13.8)$ & \\
\hline No & 364 & $19(57.6)$ & $345(86.3)$ & \\
\hline
\end{tabular}

Values are presented as number (\%).

NS, not significant.

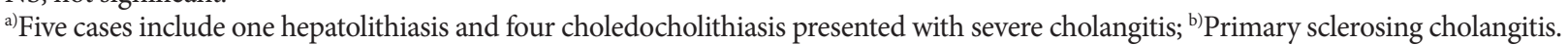

Table 5. Multivariate Analysis of Risk Factors Associated with Mortality in Acute Cholangitis Patients

\begin{tabular}{lccl}
\hline \multicolumn{1}{c}{ Variable } & p-value & Odds ratio & $95 \%$ CI \\
\hline Age & 0.740 & 1.0 & $0.9-1.0$ \\
Hospital acquired & 0.193 & 1.9 & $0.7-4.7$ \\
Severe cholangitis & 0.000 & 8.9 & $3.9-20.6$ \\
Malignant biliary obstruction & 0.000 & 7.7 & $2.8-21.2$ \\
ESBL or carbapenemase & 0.001 & 3.9 & $1.7-9.0$ \\
producers & & & \\
\hline
\end{tabular}

CI, confidence interval.

ing devices.

In this study, ESBL or carbapenemase producing bacteria isolated from blood are associated with prior biliary intervention and nosocomial infection. Failure of the enteric-biliary barrier due to stent placement may be an important factor in mixed bacterial colonization of the bile duct. ${ }^{3}$ In an animal model, sphincterotomy and/or biliary stent placement caused heavy ductal contamination. ${ }^{1}$ Prior biliary intervention including EST can make a larger inoculum of bacteriobilia, which may contribute the acquisition of ESBL- or carbapenemase producing bacteria in the condition of biliary obstruction. In this study, among 16 cases with community acquired ESBL or carbapenemase producing bacteria in blood stream, 13 cases received biliary intervention before bacteremia. Nosocomial infection has been introduced as a risk factor in previous studies of antibiotic-resistant organisms. ${ }^{21,23}$ Patients with prior hospital stay may have had more chances to be exposed to additional antibiotics and to other patients with antibiotic-resistant organisms.

Infection by antibiotic-resistant bacteria typically has a poor outcome. ${ }^{23,24}$ In this study, antibiotic-resistant bacteria were associated with mortality, independent of other prognostic factors such as malignant biliary obstruction and severe cholangitis. One study showed that a delay in the institution of appropriate antimicrobial therapy is mainly responsible for the increased mortality related to ESBL producing bacteria bloodstream infections. ${ }^{25}$ Given the prevalence of antibiotic resistance, blood and/or bile cultures are important to ensure effective antibiotic therapy for patients with acute cholangitis. Also, the empirical antibiotics used in these cases should be reconsidered, especially in patients with a high risk of harboring antibioticresistant bacteria.

\section{Conflicts of Interest}

The authors have no financial conflicts of interest.

\section{Acknowledgments}

This work was supported by the research grant of the Chungbuk National University in 2010.

\section{REFERENCES}

1. Sung JY, Leung JW, Shaffer EA, Lam K, Olson ME, Costerton JW. As- 
cending infection of the biliary tract after surgical sphincterotomy and biliary stenting. J Gastroenterol Hepatol 1992;7:240-245.

2. Bornman PC, van Beljon JI, Krige JE. Management of cholangitis. J Hepatobiliary Pancreat Surg 2003;10:406-414.

3. Rerknimitr R, Fogel EL, Kalayci C, Esber E, Lehman GA, Sherman S. Microbiology of bile in patients with cholangitis or cholestasis with and without plastic biliary endoprosthesis. Gastrointest Endosc 2002;56: 885-889.

4. Choi SH, Lee JE, Park SJ, et al. Emergence of antibiotic resistance during therapy for infections caused by Enterobacteriaceae producing AmpC beta-lactamase: implications for antibiotic use. Antimicrob Agents Chemother 2008;52:995-1000.

5. Pitout JD, Nordmann P, Laupland KB, Poirel L. Emergence of Enterobacteriaceae producing extended-spectrum beta-lactamases (ESBLs) in the community. J Antimicrob Chemother 2005;56:52-59.

6. Rodríguez-Baño J, Alcalá JC, Cisneros JM, et al. Community infections caused by extended-spectrum beta-lactamase-producing Escherichia coli. Arch Intern Med 2008;168:1897-1902.

7. Hawkey PM. Prevalence and clonality of extended-spectrum beta-lactamases in Asia. Clin Microbiol Infect 2008;14 Suppl 1:159-165.

8. Tumbarello M, Sanguinetti M, Montuori E, et al. Predictors of mortality in patients with bloodstream infections caused by extended-spectrum-beta-lactamase-producing Enterobacteriaceae: importance of inadequate initial antimicrobial treatment. Antimicrob Agents Chemother 2007;51:1987-1994.

9. Falagas ME, Rafailidis PI, Kofteridis D, et al. Risk factors of carbapenem-resistant Klebsiella pneumoniae infections: a matched case control study. J Antimicrob Chemother 2007;60:1124-1130.

10. Heo JH, Lee JH, Lee MY, et al. Bacterial identification in bile and blood of patients with acute cholangitis from benign and malignant bile duct obstruction. Korean J Gastroenterol 2002;40:53-59.

11. Flores C, Maguilnik I, Hadlich E, Goldani LZ. Microbiology of choledochal bile in patients with choledocholithiasis admitted to a tertiary hospital. J Gastroenterol Hepatol 2003;18:333-336.

12. Englesbe MJ, Dawes LG. Resistant pathogens in biliary obstruction: importance of cultures to guide antibiotic therapy. HPB (Oxford) 2005; 7:144-148.

13. Melzer M, Toner R, Lacey S, Bettany E, Rait G. Biliary tract infection and bacteraemia: presentation, structural abnormalities, causative organisms and clinical outcomes. Postgrad Med J 2007;83:773-776.

14. Demirbağ AE, Karademir A, Parlak E, et al. Multidrug resistance of isolated microorganisms in occluded bile duct stents. Turk J Gastroenterol 2007;18:33-40.

15. Bae WK, Moon YS, Kim JH, et al. Microbiologic study of the bile culture and antimicrobial susceptibility in patients with biliary tract infection. Korean J Gastroenterol 2008;51:248-254.

16. Wada K, Takada T, Kawarada Y, et al. Diagnostic criteria and severity assessment of acute cholangitis: Tokyo guidelines. J Hepatobiliary Pancreat Surg 2007;14:52-58.

17. Wikler MA; Clinical and Laboratory Standards Institute. Performance Standards for Antimicrobial Susceptibility Testing. Sixteenth Informational Supplement. Wayne: Clinical and Laboratory Standards Institute; 2006.

18. Sung JY, Costerton JW, Shaffer EA. Defense system in the biliary tract against bacterial infection. Dig Dis Sci 1992;37:689-696.

19. Negm AA, Schott A, Vonberg RP, et al. Routine bile collection for microbiological analysis during cholangiography and its impact on the management of cholangitis. Gastrointest Endosc 2010;72:284-291.

20. Tanaka A, Takada T, Kawarada Y, et al. Antimicrobial therapy for acute cholangitis: Tokyo guidelines. J Hepatobiliary Pancreat Surg 2007;14: 59-67.

21. Hawkey PM, Jones AM. The changing epidemiology of resistance. J Antimicrob Chemother 2009;64 Suppl 1:i3-i10.

22. Guembe M, Cercenado E, Alcalá L, Marín M, Insa R, Bouza E. Evolution of antimicrobial susceptibility patterns of aerobic and facultative gram-negative bacilli causing intra-abdominal infections: results from the SMART studies 2003-2007. Rev Esp Quimioter 2008;21:166-173.

23. Jeon MH, Choi SH, Kwak YG, et al. Risk factors for the acquisition of carbapenem-resistant Escherichia coli among hospitalized patients. Diagn Microbiol Infect Dis 2008;62:402-406.

24. Falagas ME, Karageorgopoulos DE. Extended-spectrum beta-lactamase-producing organisms. J Hosp Infect 2009;73:345-354.

25. Schwaber MJ, Carmeli Y. Mortality and delay in effective therapy associated with extended-spectrum beta-lactamase production in Enterobacteriaceae bacteraemia: a systematic review and meta-analysis. J Antimicrob Chemother 2007;60:913-920. 